\title{
A systematic review and meta-analysis of the association between integrated tuberculosis and Human Immuno-deficiency Virus therapy and tuberculosis treatment outcomes among adults in sub-Saharan Africa
}

Benjamin Momo Kadia ( $\sim$ benjaminmomokadia@gmail.com )

Cameroon Ministry of Health https://orcid.org/0000-0002-8566-7132

Noah Fongwen Takah

Cameroon Ministry of Health

Christian Akem Dimala

Health and Human Development (2HD) Research Network, Douala

Victoria Simms

Zimbabwe LSHTM Research Partnership

\section{Research}

Keywords: integrated, HIV, tuberculosis, treatment, outcome

Posted Date: April 8th, 2020

DOI: https://doi.org/10.21203/rs.3.rs-21573/v1

License: (a) (1) This work is licensed under a Creative Commons Attribution 4.0 International License. Read Full License 


\section{Abstract}

Background: Despite the scale-up of programmes integrating treatment of tuberculosis (TB) and Human Immuno-deficiency Virus (HIV) in sub-Saharan Africa (SSA), TB treatment outcomes in TB/HIV coinfected patients in the region remain sub-optimal.

Objective: To summarize the available evidence on the association between integrated TB/HIV treatment and TB treatment outcomes specifically, successful treatment and all-cause mortality in TB/HIV coinfected adults in SSA.

Method: A systematic review of studies published between March 2004 and 10 July 2019 was performed. Seven electronic databases including Medline, Embase and Cochrane were searched to identify interventional and observational quantitative studies reporting on integrated TB/HIV treatment in SSA. Two investigators independently screened the search output, reviewed the eligible studies, and rated the quality of eligible studies using quality assessment tools of the National Heart Lung and Blood Institute. Pooled odds ratios (ORs) were derived using random-effects meta-analysis. Heterogeneity across studies was assessed using the $\mathrm{I}^{2}$ statistic. The confidence in the pooled ORs was rated using the GRADE. The final review was reported using the PRISMA.

Results: Eleven studies including 4181 participants were retained. The studies were of moderate to good quality, with 10 being quasi-experimental and cohort. Pooling of relevant studies showed that the odds of treatment success with integration was 1.1 times (95\% Cl: 0.93-1.29; $I^{2}=74.5 \%$; $p$-value for heterogeneity $=0.001$ ) the odds of treatment success without integration and the odds of mortality with integration was 1.27 (95\% Cl 1.02-1.59; $\left.\right|^{2}=87.3 \%$; $p$-value for heterogeneity<0.0001) times the odds of mortality without integration. On sensitivity analysis, the odds of mortality with integration decreased to 1.06 (95\% Cl: $0.83-1.34 ; I^{2}=80.1 \%$; $p$-value for heterogeneity<0.0001) times the odds of mortality without integration and there was strong evidence of an association between sample size variation and heterogeneity $(p=0.01)$. Good quality studies $(4 / 11)$ tended to support the effectiveness of integrated treatment in increasing successful outcomes and decreasing mortality. Certainty in the pooled ORs was low.

Conclusion: Evidence on the effect of integrated TB/HIV treatment services on treatment success and allcause mortality in TB/HIV co-infected patients in SSA is inconclusive but the few available good quality studies tend to favour the effectiveness of these services. More robust primary studies are warranted.

\section{Introduction}

Tuberculosis (TB) is the most common opportunistic infection in persons living with HIV/AIDS (PLWHA) [1]. In 2017, it was estimated that there were 10 million incident TB disease cases worldwide, with PLWHA accounting for 900,000 (9\%) of these [2]. Sub-Saharan Africa (SSA) bears the greatest burden of HIV and TB co-infection in the world; in 2017, up to $72 \%$ of all TB patients living with HIV/AIDS resided in the region [2]. Currently, TB accounts for as high as one in three AIDS-related deaths on the global scale [3] 
and in low-income settings like SSA, it is the most common cause of death in PLWHA [4]. TB treatment outcomes in co-infected patients remain suboptimal in several low-income settings like SSA [7]: for instance, among the 900,000 co-infected patients recorded worldwide in 2017, up to 300,000 (33.3\%) died because of TB, with the majority of cases being registered in SSA [7].

There is substantial evidence indicating that patients who are co-infected with TB and HIV are more likely to experience unsuccessful TB treatment outcomes [6-8]. Studies have demonstrated that a key intervention to address this issue is to initiate and maintain HIV-infected TB patients on antiretroviral drugs [9-12]. However, in SSA, the delivery of therapy to patients who are co-infected with TB and HIV has traditionally been through separate (vertical) TB and HIV programmes [13]. This approach has been associated with diagnostic and therapeutic delays which lead to unnecessary mortality [13]. In order to foster coordination of TB/HIV treatment and improve outcomes, the integration of HIV and TB treatment services was proposed. Integrated TB/HIV treatment aims to merge treatment commodities for both TB and HIV, reduce fragmentation of TB/HIV treatment services, improve access to and quality of concurrent TB/HIV treatment and enhance the effectiveness of concurrent TB/HIV treatment [14].

In 2004, the World Health Organization (WHO) issued guidelines on collaboration between TB and HIV programmes. These guidelines sought to promote integration of TB/HIV treatment and care [15]. The guidelines were based on incomplete evidence and were thus termed provisional guidelines [16]. In 2012, WHO issued a review of these guidelines [16]. Overall, the updated guidelines present a similar framework as the interim policy but lay emphasis on establishing mechanisms for delivering integrated treatment for TB and HIV [16]. A gradual scale-up in various integration strategies has been reported following the new guidelines [17].

While acknowledging the rationale for integrating TB/HIV treatment and scaling-up integration strategies in a high burden setting like SSA, few successful strategies have been reported [18] and evidence on the downstream effects of TB/HIV treatment integration on therapeutic outcomes of TB in co-infected patients in routine clinical settings in the region remain unclear. Studies from diverse locations such as those by Gandhi et al in South Africa [19], Jack and et al in South Africa [20], Pathmanathan et al in Swaziland [21] and Musaazi et al in Uganda [22] describe high rates of successful TB treatment outcomes following treatment integration. But in all these studies, the evidence is derived from study populations with no comparison groups $[19,21,23]$ and is therefore inadequate as evidence of the effectiveness of treatment integration in improving TB outcomes. Meanwhile, some observational studies reported findings that contradict the widely upheld beneficial effects of integrating treatment services for TB and HIV. For instance, in 2014, a study conducted by Kaplan et al in Cape Town, South Africa, found no improvement in TB treatment outcomes with integration of TB and HIV treatment services [24]. In the same setting and year, Uyei et a/ reported an unexpected finding of increased odds of death and loss to follow-up in the context of cooperation between TB and HIV treatment services[25].

Pioneer systematic reviews by Legido-Quigley et al in 2012 [13] and Uyei et al in 2011 [26], provide evidence on models of delivering integrated care for TB/HIV in low-income settings but do not investigate 
the estimated effect of integrated TB/HIV treatment on TB treatment outcomes. Also, the evidence included in these reviews were essentially based on the 2004 WHO guidelines and older recommendations $[13,26]$. Consequently, there is lack of recent comprehensive reviews estimating the effect of TB/HIV treatment integration on TB treatment outcomes in SSA.

\section{Objectives}

1. To assess the association between integrated TB/HIV treatment and TB treatment success among adults who are co-infected with TB and HIV in SSA

2. To evaluate the association between integrated TB/HIV treatment and all-cause mortality occurring after TB diagnosis and before the end of TB treatment among adults who are co-infected with TB and HIV in SSA

\section{Methods}

Study design: Systematic review and meta-analysis.

Search strategy and screening: Medline, Embase, Global Health, Cochrane, Popline, Scopus, and Africa journal online databases were searched extensively to include studies published from 2004 (when WHO first issued recommendations on integrated HIV/TB treatment) till July 2019. An experienced librarian at London School of Hygiene and Tropical Medicine was involved the development and refinement of the search strategy. The search terms and their variations were used in combination are shown on table 1. Articles from the search were saved on Mendeley software and their titles, abstracts and full texts (including those found in reference lists of relevant articles) were independently screened by two reviewers. A harmonised list of studies obtained by the two reviewers was produced.

Selection criteria: Studies published in English in peer-reviewed journals were considered.

\section{Inclusion criteria}

-Population: studies involving adults who are co-infected with TB/HIV in sub-Saharan Africa -Intervention: studies reporting on integrated therapy for TB and HIV in sub-Saharan Africa

-Comparator: Adults who are co-infected with TB and HIV and receiving treatment via non-integrated treatment programmes.

-Outcomes: Studies assessing the impact of TB/HIV treatment integration on TB treatment outcomes

-Study design: randomised trials; observational studies; quantitative and qualitative studies, mixedmethods research

\section{Exclusion criteria}


-Population: studies involving pregnant women, children, patients with presumptive or unconfirmed TB, patients with multi-drug resistant TB, patients with other morbid conditions such as liver injury and renal impairment, patients with only tuberculosis or only HIV

-Intervention: studies describing treatment for only HIV or TB; studies that do not mention TB/HIV treatment in the integrated service package; studies describing integration beyond TB and HIV services -Comparator: studies with inadequate comparison groups (i.e, co-infected adults who are under nonintegrated treatment)

-Outcome: studies reporting on integrated TB/HIV treatment without describing TB treatment outcomes -Study design: Mini-reviews, editorials, letters to editors, conference abstracts, commentaries, abstracts whose full data were not be available even upon requesting from the author, unpublished manuscripts and conference abstracts, duplicate studies (for studies published with the same or different titles or in more than one journal, the most updated version was considered).

Data extraction, analysis and synthesis: A data extraction from was designed on Microsoft Excel 2016 and definitions of key terms were developed to standardise the data collection process. The extracted data was saved on the form and subsequently double-checked for accuracy by the investigator. The extracted data included:

1. Publication details such as author, publication year, journal reference, country and place of study, study period, study design and setting, study population, sample size, as well as limitations of studies.

2. Tuberculosis treatment outcomes as defined by WHO guidelines. As per the guidelines, these outcomes include 'cure', 'treatment completed', 'treatment failure', 'default', 'died' and 'transferred out'. Cure is defined as the presence of a negative sputum smear at the last month of treatment and at least on one other occasion during treatment. Treatment completion refers to a patient who completed treatment, but for whom smear examination results were not complete enough to classify the patient as cured; or based on clinical, radiological and complementary examination criteria in those patients who did not produce sputum for a smear examination. Death refers to all-cause mortality occurring after TB diagnosis and before the end of treatment. A defaulter is one who fails to collect medicines for $\geq 2$ consecutive months. According to the guidelines, successful treatment outcomes refer to the combination of 'cure' and 'treatment completed' categories [27]. This review focused on treatment success and death as outcomes.

The risk of bias and the quality of observational and interventional studies were evaluated using the corresponding assessment tools recommended by the National Heart, Lung, and Blood Institute [28]. The level of confidence in summary estimates was assessed using the Grading of Recommendations Assessment, Development and Evaluation (GRADE) approach [29]. The data extracted from quantitative studies were recorded on Microsoft Excel 2016. The association between TB/HIV treatment integration and TB treatment outcomes was derived by assessing odds ratios. For studies that only reported the percentages of TB treatment outcomes (in groups without and with treatment integration), these percentages were converted to absolute values by multiplying them by the corresponding number of 
study participants in each group. The absolute values obtained were then used to estimate odds ratios and their $95 \%$ confidence intervals [30].

For studies reporting other measures of effect such as risk ratio, these measures were converted to proportions and the proportions converted to odds ratios as explained above. The quantitative data entered in the excel spreadsheet was then exported to STATA version 15 software. Presuming the variation in the true effect of integrated treatment on TB outcomes between studies, a random effect meta-analysis was fitted to estimate the summary odds ratios and their $95 \% \mathrm{Cl}$. The analysis was conducted for treatment outcomes for which we obtained at least five effect sizes. The results of the meta-analysis were presented as forest plots and funnel plots (assessing risk of publication bias). The percentage of variation in effect estimates that was due to heterogeneity across studies was assessed using the $\mathrm{I}^{2}$ statistic. In this study, the degree of heterogeneity was interpreted as none $\left(\mathrm{I}^{2}<25 \%\right)$, low $(25 \leq$ $\left.1^{2} \leq 49 \%\right)$, moderate $\left(50 \leq \mathrm{I}^{2} \leq 74 \%\right)$ or high $\left(\mathrm{I}^{2} \geq 75 \%\right)$. For each treatment outcome, the $\mathrm{p}$-value for heterogeneity was used to determine whether heterogeneity was associated with variations in the odds ratio across studies. When methodological limitations could explain the size of the odds ratio in a study, sensitivity analysis was conducted by omitting the study and repeating the meta-analysis. Metaregression was used to assess the effect of sample size variations on summary estimates. All reported pvalues were two-sided with a significance level of 0.05 .

Reporting method: The review procedure was developed and reported as per the Preferred Reporting for Systematic Reviews and Meta-analysis (PRISMA) guidelines (supplementary file 1)

Ethical considerations: Ethical approval was not needed for the study as it is a systematic review and does not involve the collection of data from human participants.

Systematic review registration: A study protocol was submitted and registered with the International Prospective Register of Systematic Reviews (PROSPERO), under the registration number CRD42020173701.

\section{Results}

\section{Overview of search output and characteristics of studies}

Figure 1 shows the steps that were followed to arrive at the final articles included in the review. Twohundred and sixteen studies were retained for full text review after removal of duplicates, review of the reference list of relevant studies, and screening of titles and abstracts. Eleven studies assessing the association between TB/HIV treatment integration and TB treatment outcomes were retained. The included studies had a total of 4181 participants. Seven of these were of moderate quality and the rest of good quality (supplementary file 2). With regards to setting, $5 / 11$ studies were conducted in East Africa and 5/11 in Southern Africa. Five studies were exclusively from urban settings, four from rural settings and two studies were from both rural and urban settings. Regarding study designs, 6/11 studies were 
quasi-experimental (before-and-after) studies. Table 2 is a comparative data table on the studies included in the review.

\section{Association between TB/HIV treatment integration and TB treatment success}

Six of the studies (two of good quality) had data that could be used to estimate the odds of TB treatment success with implementation of integrated treatment compared to the odds of successful treatment outcomes in the absence integrated treatment. As shown in figure 2, between-study heterogeneity (variability in the estimated crude odds ratios) was moderate $\left(I^{2}=74.5 \%\right)$ and the pooled odds ratio was 1.1 (blue diamond. In TB/HIV co-infected patients, the odds of experiencing successful outcomes under treatment integration was similar to the odds of experiencing successful outcomes when no integration strategy was employed. The $95 \%$ confidence interval $(95 \% \mathrm{Cl})$ for the pooled odds ratio was $0.93-1.29$. We can be reasonably (95\%) confident that the pooled odds of treatment success following the implementation of TB/HIV treatment integration is between 0.93 to 1.29 times the odds of treatment success in the absence of a strategy to integrate therapy. The $95 \% \mathrm{Cl}$ overlaps 1 ; it is possible that the observed pooled effect is due to chance. There was strong evidence of an association between heterogeneity and variations in the odds ratios across studies $(p=0.001)$. On meta-regression, there was borderline evidence of an association between sample size variation and the observed heterogeneity $(p=0.064)$. Supplementary file 3 is a funnel plot to assess the possibility of publication bias. The data points (representing the six studies) are symmetrically distributed; there is minimal risk of publication bias.

\section{Association between TB/HIV treatment integration and all-cause mortality}

Seven studies (four of good quality) estimated the odds of mortality with integrated treatment services compared to the odds of mortality in the absence of treatment integration. As shown in figure 3 , the variability in the estimated crude odds ratios (between-study heterogeneity) was high $\left(I^{2}=87.3 \%\right)$ and the pooled odds ratio was 1.27 (blue diamond). In TB/HIV co-infected patients, the odds of death following the implementation of a treatment integration was about 1.3 times the odds of mortality in the absence of integrated treatment services. The $95 \%$ confidence interval $(95 \% \mathrm{Cl})$ for the pooled estimate was 1.02 1.59. We can be reasonably (95\%) confident that the pooled odds of death following the implementation of TB/HIV treatment integration is between 1.02 to 1.59 times the odds of mortality in the absence of integrated therapy. The $95 \% \mathrm{Cl}$ excludes 1 ; it is unlikely that the observed pooled OR is due to chance. Meta-regression showed borderline evidence of an association between sample size variation and heterogeneity $(p=0.057)$. There was very strong evidence of an association between heterogeneity and variations in the odds ratios across studies $(p<0.0001)$.

Figure 4 is the forest plot for a sensitivity analysis to evaluate whether the pooled OR for the seven studies was pulled in the direction of the OR estimated for the Hermans et al. study. When pooling was restricted to the other 6 studies, the between-study heterogeneity remained high $\left(I^{2}=80.1 \%\right)$, but the pooled OR decreased to 1.06. In TB/HIV patients, the odds of death with integrated treatment services was the 
same the odds of mortality in the absence of a strategy to deliver integrated therapy, excluding the crude OR estimated for the study by Hermans et al. The $95 \%$ confidence interval $(95 \% \mathrm{Cl})$ for the pooled OR was 0.83-1.34 (includes 1.0). We can be reasonably (95\%) confident that the pooled odds of death following the implementation of an integration strategy is between 0.83 to 1.34 times the odds of mortality in the absence of integrate therapy services. The $95 \% \mathrm{Cl}$ includes 1 ; it is possible that the observed pooled OR is due to chance. Withholding the study by Hermans et al, there was strong evidence of an association between sample size variation and the observed heterogeneity $(p=0.01)$ and there was very strong evidence of an association between heterogeneity and variations in the odds ratios across studies $(p<0.0001)$. Supplementary file 4 is a funnel plot to assess the possibility of publication bias across the studies. The data points (representing the six studies) are symmetrically distributed. The risk of publication bias is minimal.

Supplementary file 5 is the GRADE evidence profile assessing the confidence in the evidence on the estimated effects of integrating TB/HIV treatment on the TB treatment outcomes. The certainty in the evidence for each outcome was rated as low.

\section{Discussion}

This systematic review intended to summarize available evidence on the association between integrated TB/HIV treatment and TB treatment success and mortality. Eleven studies which were of moderate to good quality were included in the review and the majority were before-and-after studies based on retrospective reviews of routine programmatic data. Six studies (two being of good quality) had data on TB treatment success and pooling of these studies showed that the odds of successful outcomes was the same regardless of integration status. Nonetheless, the observed effect estimates in both good quality studies favoured the effectiveness of treatment integration in increasing treatment success. Seven studies (With four of good quality) had mortality data and pooling of the studies showed that the odds of mortality with integration was about 1.3 times the odds of mortality without integration. But when pooling was restricted to the six studies whose methodological limitations were unlikely to be associated with the effect size, the odds of mortality was the same regardless of integration status. However, the observed effect estimates in the good quality studies tended to support the effectiveness of treatment integration in decreasing all-cause mortality. The paucity of studies did not allow for sub-group analysis based on the quality of the studies. When the pooled estimates for the outcomes of interest were further assessed by taking into consideration the risk of bias, inconsistency, indirectedness, imprecision as per the GRADE, the level of confidence in all the pooled estimates was rated as low.

This study is among the scarce literature reviews that investigate the integration of TB/HIV treatment services in SSA. It contributes to addressing the issue of alarming lack of data on the performance of TB/HIV treatment integration programmes in SSA. The systematic search of up to 7 databases allowed for the assessment of a large pool of studies of varying qualities from which eligible studies were obtained. Contrary to previous systematic reviews that limited their scope to hospital-based studies and did not describe quality assessments of the studies or the confidence in the cumulative evidence $[13,26]$, 
the current review includes evidence from community-based studies and describes how the quality of included studies as well as the confidence in the measured outcomes were rated. Importantly, metaanalyses showed that there was minimal risk of publication bias, i.e, it is reasonable to consider that the studies with effect estimates on successful TB treatment and mortality included in the meta-analyses, constitute a representative sample of the available evidence on TB treatment success and all-cause mortality in integrated TB/HIV treatment programmes. As this review mainly included routine programmatic data, its findings reflect real life situations, and this is extremely useful in informing TB/HIV integration programmes on their effectiveness in reducing mortality or increasing treatment success.

Evidence from community-based studies have tended to demonstrate that integrated TB/HIV therapy leads to better clinical outcomes and use limited resources more efficiently [19, 42]. However, patients enrolled for community-based treatment are generally carefully selected and in concurrent TB/HIV therapy these patients are required to fulfil essential criteria like clinical stability, undetectable viral load and optimal CD 4 counts before being down-referred to community-based clinics [19,42,43]. As a result, community-based programmes integrating TB/HIV treatment may tend to overestimate treatment success or underestimate all-cause mortality and so the effects of such programmes on treatment outcomes should be interpreted with caution.

Meta-analyses including large randomised trials (in which TB/HIV co-infected patients are randomly assigned to integrated treatment in one arm and non-integrated models in the other arm) to evaluate the association between integrated TB/HIV treatment and TB treatment outcomes could have led to more robust findings. Nonetheless, most of the quantitative studies included in the current review were quasiexperimental (before-and-after) historical studies assessing the same intervention (integrated delivery of TB and HIV treatment). This minimal variation in the quantitative research methods and intervention of interest does not only justify the conduct of meta-analysis but contributes to the internal validity of the results of the meta-analysis. The lack of trials randomising patients to receive integrated versus vertical treatment of TB/HIV could be explained by the existing compelling evidence on the clinical benefits of early initiation of ART in HIV-infected TB patients, such that the conduct of further randomised trials in this regard could be considered unethical[9,10,44]. Even the SAPiT trial, a pioneer clinical trial that was crucial in establishing the effectiveness of early initiation of antiretrovirals (during TB treatment) on improving therapeutic outcomes was interrupted prematurely because early initiation clearly had more benefits over delayed initiation and it was deemed unethical to continue enrolling patients in the delayed initiation arm $[9,45]$. Even though it is expected that compared to vertical treatment of TB and HIV, integrated TB/HIV treatment should lead to higher or much earlier initiation of ART in co-infected patients and presumably better treatment outcomes, there is considerable evidence indicating that in routine clinical settings, there are serious shortfalls in the uptake of ART and its timeliness relative to the start of TB treatment in integrated TB/HIV clinics [21]. In routine clinical settings, there are factors such as psychosocial, economic and health system-related that impede the uptake and timely initiation of treatment in the context of integrated TB/HIV therapy and these factors ought to be addressed in order to 
optimise treatment outcomes in integrated TB/HIV programmes. Such factors tend to be controlled for in randomised clinical trials.

Most of the studies in this review involved analyses of data recorded over different periods. Thus, changes in health policy, infrastructure, technology and other contextual factors over time are expected to have played a role in influencing treatment outcomes. Regarding health policy changes, an ironic result is worth mentioning. Intensification of active finding and outcome ascertainment in patients lost to followup have been prioritised in several settings (in line with WHO guidelines) in tandem with scaling-up strategies to integrate treatment. Consequently, in settings where the guidelines are adhered to, mortality in patients lost to follow-up appears to be on the rise albeit this observation is very likely to be the result of improvements in outcome ascertainment and reporting methods. This possibly explains why studies based on historical data could observe unexpectedly higher proportions of death after implementation of an integration strategy compared to before the introduction of the strategy when outcome ascertainment in patients lost to follow-up was sub-optimal. This difference in the outcome ascertainment can lead to bias due to differential misclassification of mortality before and after treatment integration. Among the seven studies included in the analysis of the effect of treatment integration on mortality, the degree of differential misclassification in the study by Hermans et a/ was appeared to be remarkable, with the odds of mortality post-integration being as high as 6 times the odds of mortality pre-integration for comparable numbers of co-infected patients in pre-integration and post-integration groups. The relatively high odds ratio from the study by Hermans et al served as impetus to perform a sensitivity analysis in which pooling of odds ratios was restricted to the other six studies that had odds ratios well below 2.0. This yielded a marked reduction in the pooled odds ratio which then showed no statistical difference in mortality with integration status. This shows how methodological flaws in a single study could have considerable impact on pooled effect estimates and the overall interpretation of the results of a systematic review with meta-analysis.

The current systematic review has some limitations. It was not possible to obtain odds ratios adjusted for confounders in most of the quantitative studies, so pooled odds ratios were obtained from crude estimates which are unadjusted for confounders. Moreover, the data assessed in this review was not thick and the included studies did not consistently report quantitative indicators of treatment progress such as clinical staging of patients, viral load, CD4 counts. As such, even though random-effects meta-analysis was appropriately used, given the high heterogeneity in effect estimates, there was insufficient data to perform meta-regression to assess the effect of many variables on heterogeneity. Nonetheless, on sensitivity analysis, it was observed that there was strong evidence of an association between sample size variation and heterogeneity when assessing the association between integrated treatment and allcause mortality. It is also worth noting that TB/HIV integrated treatment could be regarded as one component of a larger service package and the influence of each component on treatment outcome is difficult to discern. This larger service package includes other clinical services (like psychosocial support, supervision of therapy and co-triamoxazole preventive therapy), administrative aspects such as development of guidelines and the overall organisation of services in integrated care facilities [45]. Furthermore, most of the studies in the review were retrospective studies of routine data from different 
integration strategies (albeit complete integration of TB and HIV services was reported in most studies) with flaws in documentation such as incomplete or missing data. For instance, the study by Herce et al which included 473 patients did not have documented TB treatment outcomes for up to $40 \%$ of the patients [35]. Finally, studies in this review were principally from East and Southern Africa. Therefore, generalizing the results of this study to other parts of Africa should be done with caution.

\section{Conclusion}

Based on the evidence included in this review, the role of TB/HIV treatment integration in increasing successful outcomes and decreasing mortality in TB/HIV co-infected patients was inconclusive. But these results should be interpreted with caution for a number of reasons. The available good quality studies tended to support the effectiveness of TB/HIV treatment integration in increasing successful outcomes and decreasing mortality, but these studies were few, and smaller in number than the moderate quality studies. Additionally, much of the evidence was from retrospective analyses of routine programmatic data which restrict investigators' ability to reduce confounding and other sources of bias. The cumulative evidence in this review does not indicate that TB/HIV treatment integration improved TB treatment outcome in SSA but there is low confidence in this cumulative evidence. More robust primary studies are therefore required to arrive at more conclusive evidence on the association between TB/HIV treatment integration and TB treatment outcomes. Such evidence will be crucial in updating policies and clinical guidelines on integrated TB/HIV treatment. Some important considerations that could improve on the validity of future research include: prospective data collection and follow-up of study participants over several months in order to properly report outcomes; use of impact evaluation methods that are more robust than before-and-after studies; optimal adjustments for confounders and missing/poorly reported data; and comparing integrated and non-integrated treatment services using other proxies of treatment outcomes (beyond routine WHO standards). Such proxies could include timeliness of ART uptake relative to TB treatment and TB treatment outcomes and the time between TB treatment uptake and outcomes. Future research should also assess various challenges experienced during the delivery integrated TB/HIV treatment settings since such challenges could ultimately favour negative treatment outcomes.

\section{List Of Abbreviations}

ART: Antiretroviral therapy

AIDS: Acquired Immunodeficiency Syndrome

LMICs: Low and middle-income countries

OR: Odds ratio

PLWHA: Persons living with HIV/AIDS

TB: Tuberculosis 
WHO: World Health Organisation

\section{Declarations}

Acknowledgment: Not applicable

Funding: No funding was received for the conduct of this study.

Availability of data and materials: Not applicable

\section{Authors' contributions:}

- BMK: conception of the study; literature review; data analysis and synthesis; preparation of the manuscript

- NFT: participated in the selection and quality assessment of eligible studies; assisted in data analysis and synthesis; edited the initial manuscript

- CAD: reviewed the content of the initial and final versions of the manuscript for technical and intellectual consistency

- VS: reviewed the initial manuscript for technical and intellectual consistency; critically-appraised the final versions of the manuscript

All the authors have read and approved the final version of the manuscript.

Ethics approval and consent to participate: Not applicable

Consent for publication: Not applicable

Competing interests: The authors declare that they have no competing interests

\section{References}

1. Manosuthi W, Wiboonchutikul S, Sungkanuparph S. Integrated therapy for HIV and tuberculosis. AIDS Res Ther. BioMed Central; 2016;13:1-12.

2. World Health Organisation. Global Tuberculosis Report 2018. Geneva, Switzerland. WHO 2018.

3. Joint United Nations Programme on HIV/AIDS. 2018 GLOBAL HIV STATISTICS. Geneva, Switzerland. UNAIDS 2018.

4. Mukadi YD, Maher D, Harries A. Tuberculosis case fatality rates in high HIV prevalence populations in sub-Saharan Africa. AIDS. England; 2001;15:143-52.

5. World Health Organisation. Global Tuberculosis Report 2015. Geneva, Switzerland. WHO 2015.

6. Engelbrecht MC, Kigozi NG, Chikobvu P, Botha S, van Rensburg HCJ. Unsuccessful TB treatment outcomes with a focus on HIV co-infected cases: a cross-sectional retrospective record review in a high-burdened province of South Africa. BMC Health Serv Res. England; 2017;17:470. 
7. Sanchez M, Bartholomay P, Arakaki-Sanchez D, Enarson D, Bissell K, Barreira D, et al. Outcomes of TB treatment by HIV status in national recording systems in Brazil, 2003-2008. PLoS One. 2012; 7(3) e33129

8. Ambadekar NN, Zodpey SP, Soni RN, Lanjewar SP. Treatment outcome and its attributes in TB-HIV coinfected patients registered under Revised National TB Control Program: A retrospective cohort analysis. Public Health. 2015; 129(6): 783-789

9. Abdool Karim SS, Naidoo K, Grobler A, Padayatchi N, Baxter C, Gray AL, et al. Integration of antiretroviral therapy with tuberculosis treatment. N Engl J Med. United States; 2011;365:1492-501.

10. Naidoo K, Baxter C, Abdool Karim SS. When to start antiretroviral therapy during tuberculosis treatment? Curr. Opin. Infect. Dis. 2013.

11. Howard AA, Hirsch-Moverman Y, Frederix K, Daftary A, Saito S, Gross T, et al. The START Study to evaluate the effectiveness of a combination intervention package to enhance antiretroviral therapy uptake and retention during TB treatment among TB/HIV patients in Lesotho: rationale and design of a mixed-methods, cluster-randomized tr. Glob Health Action. Stockholm; 2016;9:31543.

12. Nanteza MW, Mayanja-Kizza H, Charlebois E, Srikantiah P, Lin R, Mupere E, et al. A randomized trial of punctuated antiretroviral therapy in Ugandan HIV-seropositive adults with pulmonary tuberculosis and CD4 ${ }^{+}$T-cell counts of $\geq 350$ cells/ $\mu \mathrm{L}$. J Infect Dis. 2011;204:884-892.

13. Legido-Quigley H, Montgomery CM, Khan P, Atun R, Fakoya A, Getahun H, et al. Integrating tuberculosis and HIV services in low- and middle-income countries: A systematic review. Trop Med Int Heal. 2013;18:199-211.

14. Ansa GA, Walley JD, Siddiqi K, XiaoLin W. Assessing the impact of TB/HIV services integration on TB treatment outcomes and their relevance in TB/HIV monitoring in Ghana. Infect Dis Poverty. London; 2012;1.

15. World Health Organisation. INTERIM POLICY ON COLLABORATIVE TB/HIV ACTIVITIES. Geneva, Switzerland. WHO 2004.

16. World Health Organization. WHO policy on collaborative TB/HIV activities. Guidelines for national programmes and other stakeholders. Geneva, Switzerland. WHO 2012.

17. Manjomo RC, Mwagomba B, Ade S, Ali E, Khomani P, Bondwe P, et al. Public Health Action. 2016;::60-5.

18. Friedland G, Harries A, Coetzee D. Implementation issues in tuberculosis/HIV program collaboration and integration: 3 case studies. J Infect Dis. United States; 2007;196 Suppl:S114-23.

19. Gandhi NR, Moll AP, Lalloo U, Pawinski R, Zeller K, Moodley P, et al. Successful integration of tuberculosis and HIV treatment in rural South Africa: the Sizonq'oba study. J Acquir Immune Defic Syndr. United States; 2009;50:37-43.

20. Jack C, Lalloo U, Karim QA, Karim SA, El-Sadr W, Cassol S, et al. A pilot study of once-daily antiretroviral therapy integrated with tuberculosis directly observed therapy in a resource-limited setting. JAIDS, J Acquir Immune Defic Syndr. Hagerstown; 2004;36:929-34. 
21. Pathmanathan I, Pasipamire M, Pals S, Dokubo EK, Preko P, Ao T, et al. High uptake of antiretroviral therapy among HIV-positive TB patients receiving co-located services in Swaziland. PLoS One. San Francisco; 2018;13:e0196831.

22. Musaazi J, Sekaggya-Wiltshire C, Kiragga AN, Kalule I, Reynolds SJ, Manabe YC, et al. Sustained positive impact on tuberculosis treatment outcomes of TB-HIV integrated care in Uganda. Int $\mathrm{J}$ Tuberc Lung Dis. France; 2019;23:514-21.

23. Ferroussier O, Dlodlo RA, Capo-Chichi D, Boillot F, Gninafon M, Trebucq A, et al. Results of rapid and successful integration of HIV diagnosis and care into tuberculosis services in Benin. Int $\mathrm{J}$ Tuberc Lung Dis. Paris; 2013;17:1405-10.

24. Kaplan R, Caldwell J, Bekker LG, Jennings K, Lombard C, Enarson DA, et al. Integration of TB and ART services fails to improve TB treatment outcomes: Comparison of ART/TB primary healthcare services in Cape Town, South Africa. South African Med J. 2014;104:204-9.

25. Uyei J, Coetzee D, Macinko J, Weinberg SL, Guttmacher S. The influence of integrated tuberculosis and human immunodeficiency virus service delivery on patient outcomes. Int $\mathrm{J}$ Tuberc Lung Dis. France; 2014;18:315-21.

26. Uyei J, Coetzee D, Macinko J, Guttmacher S. Integrated delivery of HIV and tuberculosis services in sub-Saharan Africa: A systematic review. Lancet Infect Dis. Elsevier Ltd; 2011;11:855-67.

27. World Health Organisation. Treatment of tuberculosis: guidelines for national programme. 4Th Ed. 2010. Geneva, Switzerland. WHO 2010.

28. National Heart Lung and Blood Institute. Quality Assessment Tool for Observational Cohort and Cross-Sectional Studies. Bethesda, Maryland, United States of America. NIH 2014.

29. Guyatt G, Oxman AD, Sultan S, Brozek J, Glasziou P, Alonso-coello P, et al. GRADE guidelines: 11 . Making an overall rating of confidence in effect estimates for a single outcome and for all outcomes. 2013;66.

30. Thorlund K, Walter SD, Johnston BC, Furukawa TA, Guyatt GH. Pooling health-related quality of life outcomes in meta-analysis-a tutorial and review of methods for enhancing interpretability. Res Synth Methods. 2011; 2 (3): 188-203

31. Burnett SM, Zawedde-Muyanja S, Hermans SM, Weaver MR, Colebunders R, Manabe YC. Effect of TB/HIV integration on TB and HIV indicators in rural Ugandan health facilities. JAIDS, J Acquir Immune Defic Syndr. Hagerstown; 2018;79:605-11.

32. Schwartz AB, Tamuhla N, Steenhoff AP, Nkakana K, Letlhogile R, Chadborn TR, et al. Outcomes in HIV-infected adults with tuberculosis at clinics with and without co-located HIV clinics in Botswana. Int J Tuberc Lung Dis. Paris; 2013;17:1298-303.

33. Herce ME, Morse J, Luhanga D, Harris J, Smith HJ, Besa S, et al. Integrating HIV care and treatment into tuberculosis clinics in Lusaka, Zambia: results from a before-after quasi-experimental study. BMC Infect Dis. England; 2018;18:536.

34. Conradie $\mathrm{H}$, Khati $\mathrm{P}$, Pharoah $\mathrm{H}$, Adams S. Integrating tuberculosis/HIV treatment: an evaluation of the tuberculosis outcomes of patients co-infected with tuberculosis and HIV in the Breede Valley 
subdistrict. South African Fam Pract. Lyttelton; 2013;55:478-9.

35. Schulz SA, Draper HR, Naidoo P. A comparative study of tuberculosis patients initiated on ART and receiving different models of TB-HIV care. Int J Tuberc Lung Dis 17(12):1558-1563

36. Hermans SM, Castelnuovo B, Katabira C, Mbidde P, Lange JMA, Hoepelman AIM, et al. Integration of HIV and TB services results in improved TB treatment outcomes and earlier prioritized ART initiation in a large urban HIV clinic in Uganda. J Acquir Immune Defic Syndr; 2012;60:e29-35.

37. Kerschberger B, Hilderbrand K, Boulle AM, Coetzee D, Goemaere E, De Azevedo V, et al. The effect of complete integration of HIV and TB services on time to initiation of antiretroviral therapy: a beforeafter study. PLoS One. United States; 2012;7:e46988.

38. Ndagijimana A, Rugigana E, Uwizeye CB, Ntaganira J. One-stop TB-HIV services evaluation in Rwanda: comparison of the 2001-2005 and 2006-2010 cohorts. Public Heal Action. Paris; 2015;5:209-13.

39. Owiti P, Zachariah R, Bissell K, Kumar AM V, Diero L, Carter EJ, et al. Integrating tuberculosis and HIV services in rural Kenya: uptake and outcomes. Public Heal Action. Paris; 2015;5:36-44.

40. Jacobson KB, Moll AP, Friedland GH, Shenoi S V. Successful Tuberculosis Treatment Outcomes among HIV/TB Coinfected Patients Down-Referred from a District Hospital to Primary Health Clinics in Rural South Africa. PLoS One. United States; 2015;10:e0127024.

41. Frasca K, Cohn J. Integration of HIV and tuberculosis in the community. J Int Assoc Provid AIDS Care. United States; 2014;13:534-8.

42. Boulle A, Clayden P, Cohen K, Cohen T, Conradie F, Dong K, et al. Prolonged deferral of antiretroviral therapy in the SAPIT trial: did we need a clinical trial to tell us that this would increase mortality? South African Med J; 2010;100:566-70.

43. Naidoo A, Naidoo K, Yende-Zuma N, Gengiah TN, Padayatchi N, Gray AL, et al. Changes to antiretroviral drug regimens during integrated TB-HIV treatment: Results of the SAPiT trial. Antivir Ther. 2014; 19(2): 161-169

44. World Health Organisation; Joint United Nations Programme on HIV/AIDS; United Nations International Children's Emergency Fund. Scaling up priority HIV/AIDS interventions in the health sector. Geneva, Switzerland. WHO 2010.

45. Uyei J, Coetzee D, Macinko J, Weinberg SL, Guttmacher S. Measuring the degree of integrated tuberculosis and HIV service delivery in Cape Town, South Africa. Health Policy Plan. England; 2014;29:42-55.

\section{Tables}

Table 1: Search strategy for systematic review and meta-analysis of the association between integrated TB/HIV treatment and TB treatment outcomes (Search terms and subject headings are in Medline format but were appropriately modified when searching other databases) 


\section{Search Query}

\#1 Integrat* OR joint OR collaborat* OR concurrent OR concomitant

\#2 Treat* OR therap* OR care OR service OR manag*

\#3 'Human immun?deficiency virus' OR HIV OR AIDS OR 'Acquired immune?deficiency syndrome' OR anti? retroviral

\#4 Tuberculosis OR 'Mycobacterium tuberculosis' OR 'Pulmonary tuberculosis' OR TB OR anti? tubercul*

\#5 Africa OR Algeria OR Angola OR Benin OR Botswana OR Burkina Faso OR Burundi OR Cameroon OR Cape Verde OR Central African Republic OR Chad OR Comoros OR Congo OR Democratic Republic of Congo OR Djibouti OR Egypt OR Equatorial Guinea OR Eritrea OR Ethiopia OR Gabon OR Gambia OR Ghana OR Guinea OR Guinea Bissau OR Ivory Coast OR Cote d'Ivoire OR Jamahiriya OR Jamahiryia OR Kenya OR Lesotho OR Liberia OR Libya OR Libia OR Madagascar OR Malawi OR Mali OR Mauritania OR Mauritius OR Mayotte OR Morocco OR Mozambique OR Mocambique OR Namibia OR Niger OR Nigeria OR Principe OR Reunion OR Rwanda OR Sao Tome OR Senegal OR Seychelles OR Sierra Leone OR Somalia OR South Africa OR St Helena OR Sudan OR Swaziland OR Tanzania OR Togo OR Tunisia OR Uganda OR Western Sahara OR Zaire OR Zambia OR Zimbabwe OR Central Africa OR Central African OR West Africa OR West African OR Western Africa OR Western African OR East Africa OR East African OR Eastern Africa OR Eastern African OR North Africa OR North African OR Northern Africa OR Northern African OR South African OR Southern Africa OR Southern African OR subSaharan Africa OR subSaharan African OR sub-Saharan Africa OR sub-Saharan African

Final \#1 AND \#2 AND \#3 AND \#4 AND \#5 search

Table 2: Comparative data table on studies included in the systematic review and meta-analysis of the association between integrated TB/HIV treatment and TB treatment outcomes 
Participants' Males age
Summary of findings

Study limitation

Year, country and participants

(a)

To determine whether TB

2018, treatment outcomes and antiretroviral initiation of TB/HIV-coinfected

Uganda [31] patients are associated with TB/HIV integration status at rural health facilities.

Cross-sectional study involving 296 patients (117 under nonintegrated care, and 179 under integrated care) in 14 rural health facilities drawn from all regions of Uganda

\begin{tabular}{|l|l|l|}
\hline $33^{+}$ & 57.8 & TB \\
& & int \\
& & wa \\
& & \\
& & ass
\end{tabular}

TB/HIV
integratio
was
associated

with lower

mortality but

not with

antiretroviral

initiation, TB

treatment

success, lost

to follow-up, or failure.

Schwartz

2013,

Botswana

[32]

To determine if starting

anti-tuberculosis

treatment at clinics

without co-located HIV

clinics would delay time

to highly active

antire troviral therapy

initiation and be

associated with lower

survival compared to

starting anti-tuberculosis

treatment at clinics with on-site HIV clinics.

Gandhi

2009,

integrated TB and HIV

treatment via concurrent

home-based care

South

Africa[19]

2018

Zambia[33]

To assess the feasibility

of integrating HIV care

and treatment into $\mathrm{TB}$

clinics and to evaluate the

effects of the intervention

on timely linkage to HIV

care, early ART uptake,

and TB treatment

outcomes.

Historical cohort study

of 439 patients (259

from clinics without and

80 from clinics with on-

site HIV) in public

clinics in Greater

Gaborone (urban area)

-integrated:

$35.5^{+}$

-non-

integrated:

$35^{+}$

ran

Prospective cohort

study of 119

TB/HIV-coinfected patients in rural KwaZulu-Natal with once-daily antiretroviral therapy concurrently with TB therapy by home-based,

modified directly observed therapy. Quasi-experimental study of routine program data for 473 patients to estimate outcomes before (June 1, 2010-January 31, 2011: 248 patients) and after (August 1, 2011March 31, 2012: 225 patients) the intervention in $2 \mathrm{~TB}$ clinics in Lusaka (urban area)
Mortality did Lack of

not differ

between

clinics

without or

with on-site

HIV clinics

nor did

median time

to

antiretroviral

initiation.

This model of

integration

resulted in

excellent TB

and HIV

outcomes

including

adherence.
Several sources

of bias could not

be controlled

especially

because of the

retrospective

data collection

with many

missing

variables

generalizability

to rural areas,

some bias due

to missing data,

some

confounders

could not be

controlled for
No

randomisation;

outcome

measurement

bias; small

sample size
Substantial

Integration

using a 'one-

stop shop'

model

-non-

integrated:

$33.7^{*}$

increased

linkage to

HIV care,

rates of early

ART

initiation,

and TB

treatment

success

among

patients with

HIV-

associated missing data on

TB treatment

outcomes; also,

important

confounders

were not

adjusted for 


\begin{tabular}{|c|c|c|c|c|c|c|}
\hline & & & & & $\begin{array}{l}\text { TB in Lusaka, } \\
\text { Zambia }\end{array}$ & \\
\hline $\begin{array}{r}\text { Conradie } \\
2013, \\
\text { South } \\
\text { Africa[34] }\end{array}$ & $\begin{array}{l}\text { To compare tuberculosis } \\
\text { outcomes of patients who } \\
\text { were co-infected with } \\
\text { tuberculosis and HIV and } \\
\text { attending an integrated } \\
\text { tuberculosis/HIV clinic, to } \\
\text { those of patients who } \\
\text { were co-infected with } \\
\text { tuberculosis and HIV who } \\
\text { continued to receive } \\
\text { tuberculosis treatment at } \\
\text { their local clinic. }\end{array}$ & $\begin{array}{l}\text { Historical cohort study } \\
\text { involving data on } 98 \\
\text { patients: } 42 \text { in the } \\
\text { tuberculosis /HIV } \\
\text { integrated clinic and } 56 \\
\text { who received their } \\
\text { tuberculosis treatment } \\
\text { at the local clinic in } \\
\text { Breed valley subdistrict } \\
\text { (both rural and urban } \\
\text { areas were included) }\end{array}$ & $33.7 *$ & 45.0 & $\begin{array}{l}\text { There was a } \\
\text { significantly } \\
\text { better } \\
\text { tuberculosis } \\
\text { outcome in } \\
\text { the cohort } \\
\text { receiving } \\
\text { integrated } \\
\text { treatment }\end{array}$ & $\begin{array}{l}\text { Unmatched } \\
\text { groups; use of } \\
\text { historical data }\end{array}$ \\
\hline $\begin{array}{r}\text { Schulz } \\
2013, \\
\text { South } \\
\text { Africa[35] }\end{array}$ & $\begin{array}{l}\text { To compare the outcomes } \\
\text { of coinfected patients } \\
\text { starting antiretroviral } \\
\text { treatment in a } \\
\text { tuberculosis hospital who } \\
\text { received different models } \\
\text { of care. }\end{array}$ & $\begin{array}{l}\text { Prospective cohort } \\
\text { study of } 271 \text { co-infected } \\
\text { patients receiving } \\
\text { either integrated care } \\
\text { or the vertical care in a } \\
\text { rural setting }\end{array}$ & $\begin{array}{l}\text {-integrated: } \\
\qquad 35.4^{*} \\
\text {-non- } \\
\text { integrated: } \\
\text { 34.6* }\end{array}$ & 39.9 & $\begin{array}{l}\text { Patient } \\
\text { outcomes } \\
\text { were better } \\
\text { when TB and } \\
\text { HIV care was } \\
\text { received } \\
\text { from the } \\
\text { same service } \\
\text { provider at } \\
\text { the same } \\
\text { visit } \\
\text { (integrated } \\
\text { care) }\end{array}$ & $\begin{array}{l}\text { Outcomes } \\
\text { occurring after } 6 \\
\text { months were not } \\
\text { assessed; poor } \\
\text { quality of } \\
\text { routine data } \\
\text { used; purposive } \\
\text { selection of } \\
\text { study site } \\
\text { increased risk } \\
\text { of selection } \\
\text { bias. }\end{array}$ \\
\hline $\begin{array}{r}\text { Hermans } \\
2012, \\
\text { Uganda[36] }\end{array}$ & $\begin{array}{l}\text { To evaluate antiretroviral } \\
\text { therapy initiation and } \\
\text { tuberculosis treatment } \\
\text { outcomes before ( } 2007 \text { ) } \\
\text { and after (2009) the } \\
\text { implementation of an } \\
\text { integrated TB/HIV clinic }\end{array}$ & $\begin{array}{l}\text { Historical cohort study } \\
\text { of } 712 \text { patients: } \\
\text { routinely collected data } \\
\text { for } 366 \text { patients } \\
\text { initiating TB treatment } \\
\text { in } 2009 \text { and with TB } \\
\text { register data for } 346 \\
\text { patients in } 2007 \text { in a } \\
\text { large clinic in } \\
\text { Makerere Uganda } \\
\text { (urban area) }\end{array}$ & $\begin{array}{l}\text {-integrated: } \\
\text { 36.8* } \\
\text {-non- } \\
\text { integrated: } \\
\text { 37.0* }\end{array}$ & 48.7 & $\begin{array}{l}\text { Treatment } \\
\text { integration } \\
\text { improved } \\
\text { tuberculosis } \\
\text { treatment } \\
\text { outcomes } \\
\text { and led to } \\
\text { earlier } \\
\text { initiation of } \\
\text { antiretroviral } \\
\text { therapy }\end{array}$ & $\begin{array}{l}\text { use of routinely } \\
\text { collected data } \\
\text { with issues of } \\
\text { missing data } \\
\text { and limitations } \\
\text { in outcome } \\
\text { ascertainment; }\end{array}$ \\
\hline $\begin{array}{l}\text { Kerschberger } \\
2012, \text { South } \\
\text { Africa[37] }\end{array}$ & $\begin{array}{l}\text { 1) to compare the time } \\
\text { from the start } \\
\text { of tuberculosis treatment } \\
\text { to antiretroviral therapy } \\
\text { initiation in TB/HIV co- } \\
\text { infected adults before and } \\
\text { after complete integration } \\
\text { of TB and HIV services } \\
\text { 2) to describe a "one stop } \\
\text { shop" model of fully } \\
\text { integrated TB and HIV } \\
\text { services. }\end{array}$ & $\begin{array}{l}\text { Historical review of } \\
\text { data on } 188 \text { co-infected } \\
\text { patients in a primary } \\
\text { care clinic in a South } \\
\text { African township (urban } \\
\text { area) }\end{array}$ & $35^{+}$ & 49.5 & $\begin{array}{l}\text { Complete } \\
\text { integration } \\
\text { increased } \\
\text { the rate of } \\
\text { antiretroviral } \\
\text { initiation and } \\
\text { shortened } \\
\text { time to } \\
\text { antiretroviral } \\
\text { initiation. }\end{array}$ & $\begin{array}{l}\text { no } \\
\text { randomization } \\
\text { leading to } \\
\text { increased risk } \\
\text { of sampling }\end{array}$ \\
\hline $\begin{array}{r}\text { Ndagijimana } \\
2015, \\
\text { Rwanda[38] }\end{array}$ & $\begin{array}{l}\text { To evaluate one-stop TB- } \\
\text { HIV services in } \\
\text { Rwanda by comparing the } \\
\text { TB treatment outcomes } \\
\text { before and after their } \\
\text { implementation }\end{array}$ & $\begin{array}{l}\text { Historical (before-and- } \\
\text { after) study in } 12 \text { public } \\
\text { facilities in rural and } \\
\text { urban areas of Rwanda } \\
\text { involving } 888 \text { patients: } \\
413 \text { post-intervention } \\
\text { cases and } 475 \text { pre- } \\
\text { intervention cases }\end{array}$ & ------ & ----- & $\begin{array}{l}\text { One-stop } \\
\text { integrated } \\
\text { services } \\
\text { were } \\
\text { operational } \\
\text { in all the } \\
\text { facilities. TB } \\
\text { treatment }\end{array}$ & $\begin{array}{l}\text { Poor } \\
\text { documentation: } \\
\text { missing data } \\
\text { and outcome } \\
\text { ascertainment; } \\
\text { limited control } \\
\text { for confounders; }\end{array}$ \\
\hline
\end{tabular}




\begin{tabular}{|c|c|c|c|c|c|c|}
\hline & & & & & $\begin{array}{l}\text { outcomes } \\
\text { after } \\
\text { the } \\
\text { intervention } \\
\text { were } \\
\text { comparable } \\
\text { before the } \\
\text { intervention. }\end{array}$ & $\begin{array}{l}\text { few facilities } \\
\text { were enrolled. }\end{array}$ \\
\hline $\begin{array}{r}\text { Owiti } \\
\text { 2015, } \\
\text { Kenya[39] }\end{array}$ & $\begin{array}{l}\text { To assess the uptake and } \\
\text { timing of cotrimoxazole } \\
\text { preventive therapy and } \\
\text { antiretroviral treatment } \\
\text { as well as anti- } \\
\text { tuberculosis treatment } \\
\text { outcomes } \\
\text { among HIV-infected TB } \\
\text { patients before and after } \\
\text { the introduction of } \\
\text { integrated TB-HIV care. }\end{array}$ & $\begin{array}{l}\text { Before-and-after study } \\
\text { of routine data on } 797 \\
\text { patients: } 347 \text { pre- } \\
\text { integration (March- } \\
\text { October 2010) and } 450 \\
\text { post-integration } \\
\text { (March-October 2012) } \\
\text { cases in } 17 \text { rural public } \\
\text { health facilities in } \\
\text { Western Kenya }\end{array}$ & $\begin{array}{l}\text {-integrated: } \\
34^{+} \\
\text {-non- } \\
\text { integrated: } \\
35^{+}\end{array}$ & 51.6 & $\begin{array}{l}\text { Integration } \\
\text { of TB and } \\
\text { HIV services } \\
\text { enhanced } \\
\text { uptake and } \\
\text { reduced } \\
\text { delay in } \\
\text { instituting } \\
\text { CPT and ART } \\
\text { in rural } \\
\text { health } \\
\text { facilities. }\end{array}$ & $\begin{array}{l}\text { Difficult to } \\
\text { compare } \\
\text { outcomes before } \\
\text { and after } \\
\text { introduction of } \\
\text { individual } \\
\text { models } \\
\text { presented in } \\
\text { study. Lack of } \\
\text { comparisons of } \\
\text { biochemical } \\
\text { data such as } \\
\text { viral load. The } \\
\text { before-and-after } \\
\text { design may have } \\
\text { introduced } \\
\text { temporal trends } \\
\text { that are not } \\
\text { controlled for. }\end{array}$ \\
\hline $\begin{array}{r}\text { Jack } \\
2004, \\
\text { South } \\
\text { Africa[20] }\end{array}$ & $\begin{array}{l}\text { To determine the } \\
\text { feasibility and } \\
\text { effectiveness of } \\
\text { integrating antiretroviral } \\
\text { therapy into existing } \\
\text { tuberculosis directly } \\
\text { observed therapy } \\
\text { programs }\end{array}$ & $\begin{array}{l}\text { Prospective study of } 20 \\
\text { co-infected patients in } \\
\text { an urban tuberculosis } \\
\text { clinic }\end{array}$ & $31 *$ & 25.0 & $\begin{array}{l}\text { Integrating } \\
\text { the } \\
\text { programmes } \\
\text { was feasible, } \\
\text { led to high } \\
\text { treatment } \\
\text { success and } \\
\text { facilitated } \\
\text { monitoring of } \\
\text { antiretroviral } \\
\text { treatment } \\
\text { outcomes }\end{array}$ & $\begin{array}{l}\text { lack of } \\
\text { generalizability: } \\
\text { small sample } \\
\text { size and only } \\
\text { one facility used }\end{array}$ \\
\hline & \\
\hline
\end{tabular}

Figures 


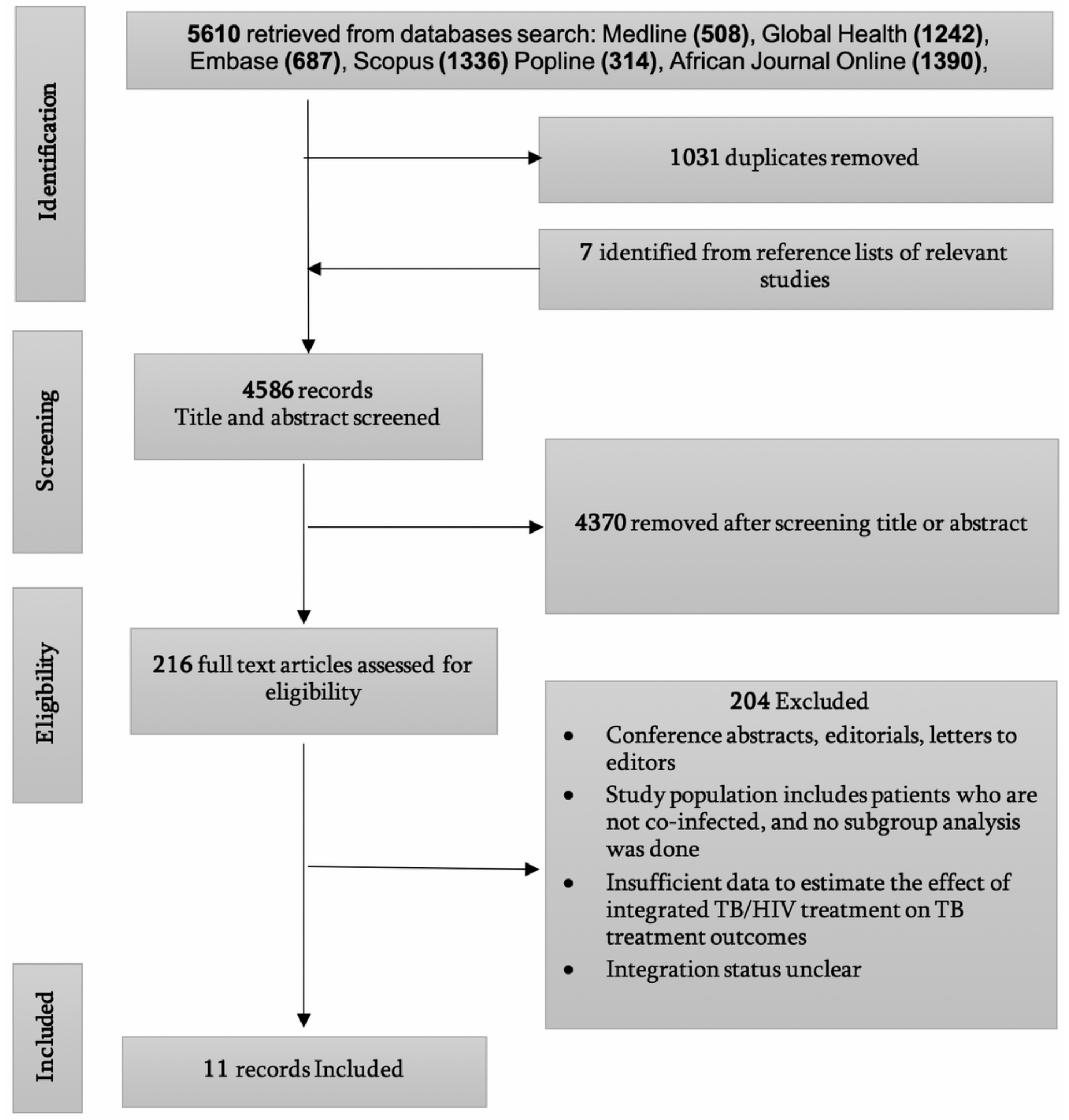

Figure 1

PRISMA flow chart showing steps to arrive at the studies included in the systematic review and metaanalysis of the association between TB/HIV treatment integration and TB treatment outcomes in subSaharan Africa 


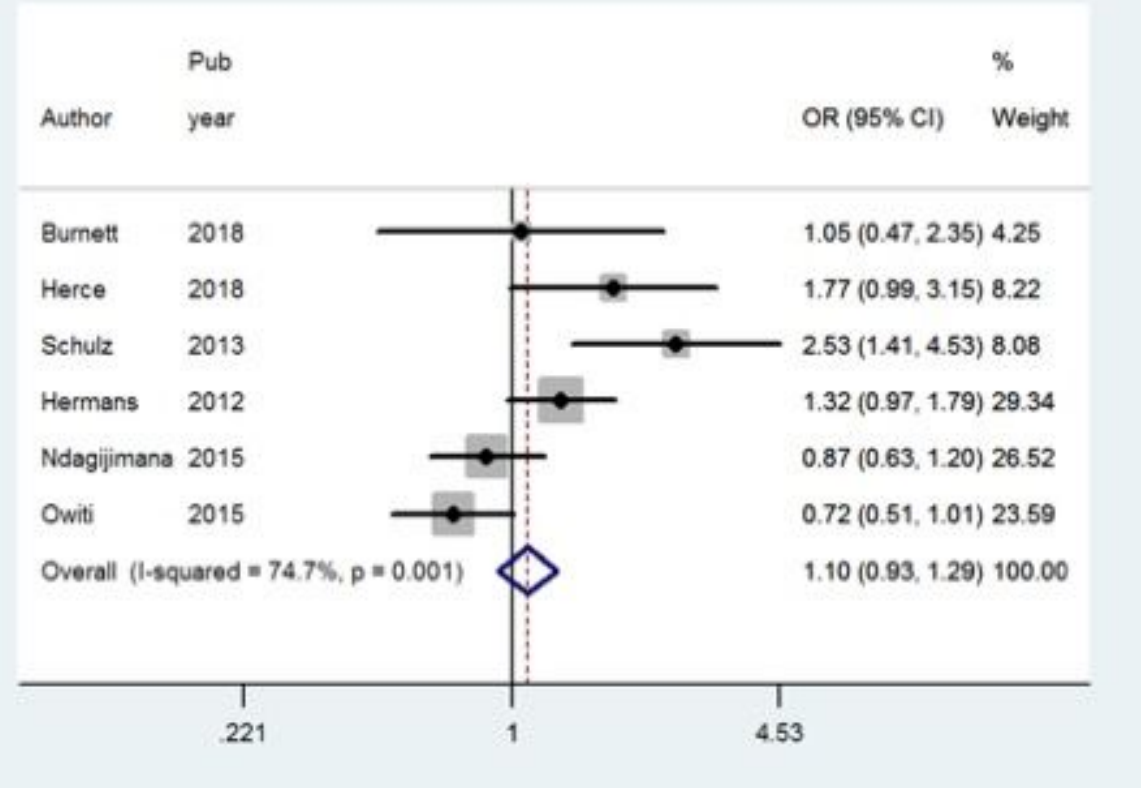

Figure 2

Forest plot showing individual and pooled odds ratios on the association between integrated TB/HIV treatment and successful TB treatment outcome

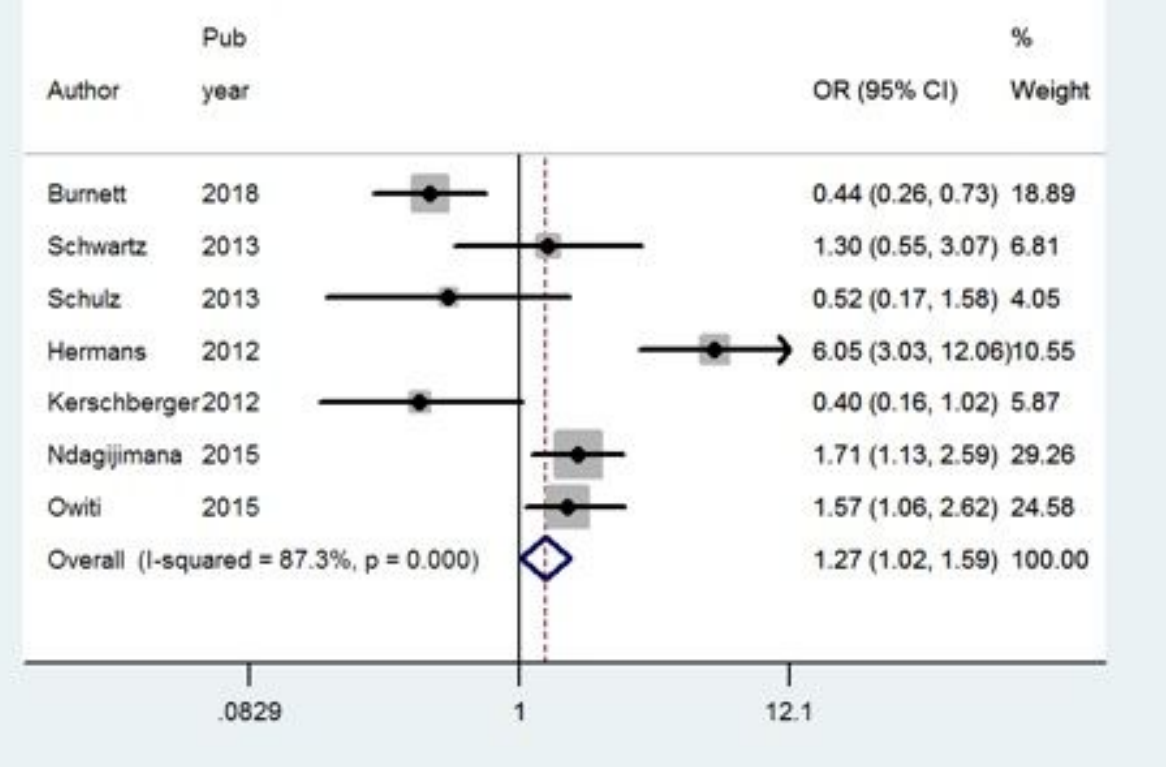

Figure 3

Forest plot showing individual and pooled odds ratios on the association between integrated TB/HIV treatment and mortality 


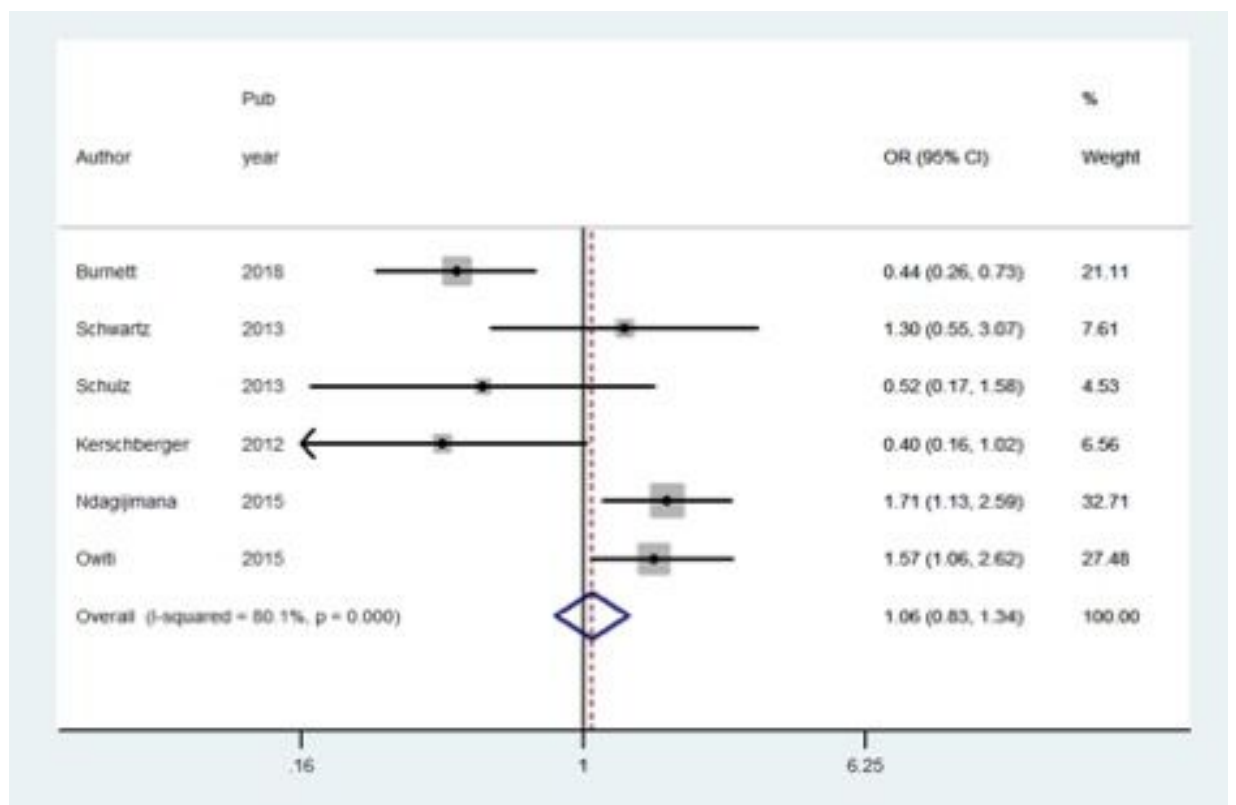

Figure 4

Figure 4: Forest plot of sensitivity analysis on the association between integrated TB/HIV treatment and mortality

\section{Supplementary Files}

This is a list of supplementary files associated with this preprint. Click to download.

- SuppFiles.zip 